\title{
Epoxy/anhydride thermosets modified with end-capped star polymers with poly(ethyleneimine) cores of different molecular weight and poly(E-caprolactone) arms
}

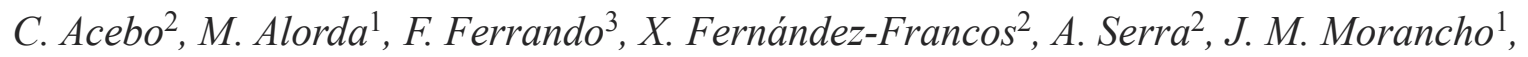 \\ J. M. Salla ${ }^{1}$, X. Ramis ${ }^{1 *}$ \\ ${ }^{1}$ Thermodynamics Laboratory, Heat Engines Department, ETSEIB, Universitat Politècnica de Catalunya, Av. Diagonal \\ 647, 08028 Barcelona, Spain \\ ${ }^{2}$ Department of Analytical and Organic Chemistry, Universitat Rovira i Virgili, C/ Marcel·lí Domingo s/n, 43007, \\ Tarragona, Spain. \\ ${ }^{3}$ Department of Mechanical Engineering, Universitat Rovira i Virgili, Països Catalans 26, 43007 Tarragona, Spain
}

Received 12 March 2015; accepted in revised form 1 May 2015

\begin{abstract}
Multiarm star polymers, with a hyperbranched poly(ethyleneimine) (PEI) core and poly( $\varepsilon$-caprolactone) (PCL) arms end-capped with acetyl groups were synthesized by ring-opening polymerization of $\varepsilon$-caprolactone from PEI cores of different molecular weight. These star polymers were used as toughening agents for epoxy/anhydride thermosets. The curing process was studied by calorimetry, thermomechanical analysis and infrared spectroscopy. The final properties of the resulting materials were determined by thermal and mechanical tests. The addition of the star polymers led to an improvement up to $130 \%$ on impact strength and a reduction in the thermal stresses up to 55\%. The structure and molecular weight of the modifier used affected the morphology of the resulting materials. Electron microscopy showed phase-separated morphologies with nano-sized fine particles well adhered to the epoxy/anhydride matrix when the higher molecular weight modifier was used.
\end{abstract}

Keywords: thermosetting resins, star polymers, epoxy resin, toughness, thermal stress

\section{Introduction}

Epoxy resins are extensively used in technological fields such as electricity and electronics. They are employed as adhesives, matrices in advanced composites, surface coatings and device assemblies because of their combination of high strength and stiffness, excellent corrosion resistance and good electrical properties [1-3]. However, their inherent rigidity and high crosslinking density makes them brittle, thus limiting their potential range of applications. In addition, when epoxy thermosets are used as coatings, thermal stresses generated from the mismatch between the thermal expansion coefficients
(CTE) of the coating and of the metallic substrate can lead to the appearance of defects that can limit their service life, such as the generation of microvoids and microcracks, the loss of adhesion due to warping. Thermal stress generated during cooling from the curing temperature down to operating conditions, typically room temperature, tends to be more severe than that consequence of heating or during service at constant temperature, especially when the temperature is below glass transition temperature $\left(T_{\mathrm{g}}\right)$ of the thermoset [4].

One of the most successful routes towards toughness improvement is to incorporate polymeric mod-

\footnotetext{
${ }^{*}$ Corresponding author, e-mail: ramis@mmt.upc.edu (C) BME-PT
} 
ifiers into the thermosetting matrix to form fine morphological structures. Some effective polymer modifiers are liquid rubber [5], thermoplastics [6] or coreshell particles [7]. In general, these modifiers are initially miscible with the uncured thermoset precursors but partially or completely phase-separate to typically form spherical structures or bicontinuous structures. The problem of this strategy is a sharp increase of the viscosity of the blends, the drop in the modulus and glass transition temperature and sometimes the poor interfacial adhesion between phases. Recently, a significant toughening effect has been achieved without compromising other properties and processability by using dendritic polymers, especially if the structure and properties of the modifier have been tailored to enhance the physical and chemical interaction between them and the matrix. The improvement in toughness can be achieved by chemically induced phase separation (CIPS) or by in situ homogeneous reinforcing and toughening mechanism, but in both cases covalent linkages or a good compatibility between the modifier and the matrix are necessary [8-16].

The thermal stresses generated during cooling of thermosetting coatings applied over metal can be minimized by reducing the CTE and elastic modulus in the glassy state of the coating, as well as by decreasing its $T_{\mathrm{g}}$, which in certain applications may not be desired. We recently reported the use of multiarm stars with poly(ethyleneimine) core and poly( $\varepsilon$ caprolactone) or poly(lactide) arms as modifiers in the curing of DGEBA using a tertiary amine as anionic curing agent $[17,18]$. Upon addition of the modifiers, the decrease on $T_{\mathrm{g}}$ and glassy modulus led to a significant reduction in internal stresses, in spite of the increase in the glassy CTE. In another work, it could be seen that the addition of hyperbranched poly(ester-amide)s to epoxy/anhydride systems allowed reaching a significant reduction of the CTE in the glassy state and consequently on the thermal stress [19], the effect being more important when higher molecular weight modifiers were used. Recently, we used multiarm star polymers with hyperbranched poly(ethyleneimine) core and poly( $\varepsilon$ caprolactone) arms of different length with reactive and unreactive terminal groups as modifiers of epoxy/ anhydride thermosets [20]. The overall stresses, measured on a steel substrate using the beam bending technique, were significantly reduced with modifiers containing reactive hydroxyl terminal groups and low degree of polymerization of the $\operatorname{poly}(\varepsilon-$ caprolactone) arms.

Taking all these precedents into account, in the present work we synthesized, following the 'core-first' approach, multiarm star polymers with hyperbranched poly(ethyleneimine) cores of different molecular weight and poly( $\varepsilon$-caprolactone) short arms. All the end hydroxyl groups resulting from the polymerization of $\varepsilon$-caprolactone were endcapped with acetyl moieties, but some amine groups of the poly(ethyleneimine) remain unmodified and can potentially react with epoxy groups. These multiarm star polymers were used to modify diglycidylether of bisphenol $\mathrm{A} /$ methyl hexahydrophthalic anhydride formulations in the presence of benzyl dimethyl amine as catalyst.

The synthesis of an amphiphilic modifier with hydrophilic core and hydrophobic shell, aimed at reaching phase-separated morphologies. The existence of reactive amino groups in the hyperbranched core would permit the incorporation of the modifier into the network structure, enhancing the interfacial adhesion between phases, if present. Moreover, the hydrophobic poly(E-caprolactone) arms could contribute to the good interfacial adhesion between the hydrophobic matrix and the modifier-rich phase. To summarize, the goal of the present work is to enhance the toughness and reduce the internal stress in epoxy/ anhydride formulations using amphiphilic star polymers with cores of different molecular weight, endcapped arms and reactive amine groups in the core structure.

The curing process was studied by calorimetry, infrared spectroscopy and thermomechanical analysis and the curing kinetics was analyzed by modelfree and model-fitting methods. The final properties of the resulting materials were characterized by means of thermogravimetry, thermomechanical analysis and electron microscopy on the fracture surface. Impact resistance was evaluated by Izod impact tests and thermal stresses were estimated on the basis of CTE, $T_{\mathrm{g}}$ and elastic modulus measurements.

\section{Experimental \\ 2.1. Materials}

Poly(ethyleneimine) (PEI) Lupasol ${ }^{\circledR} \mathrm{FG} \quad\left(M_{\mathrm{w}}=\right.$ $800 \mathrm{~g} / \mathrm{mol}$, data sheet) and Lupasol ${ }^{\mathbb{R}} \mathrm{WF}\left(M_{\mathrm{w}}=\right.$ $25000 \mathrm{~g} / \mathrm{mol}$, data sheet) were kindly donated by BASF (Ludwigshafen, Germany) and used without 
further purification. From the molecular weight of the polymer and of the repeating unit, average degrees of polymerization of 18.3 for Lupasol ${ }^{\circledR} \mathrm{FG}$ and 581.4 for Lupasol ${ }^{\circledR} \mathrm{WF}$ were calculated. According to the data sheet, the relationship $\left(\mathrm{NH}_{2} / \mathrm{NH} / \mathrm{N}\right)$ was $(1 / 0.82 /$ $0.53)$ for Lupasol ${ }^{\circledR} \mathrm{FG}$ and $(1 / 1.2 / 0.76)$ for Lupa$\mathrm{sol}^{\circledR} \mathrm{WF}$, therefore the equivalent number of primary, secondary and tertiary amines is $10,8.4$, and $5.3 \mathrm{meq} / \mathrm{g}$ for Lupasol ${ }^{\circledR} \mathrm{FG}$ and 8.0 , 9.6, and $6.1 \mathrm{meq} / \mathrm{g}$ for Lupasol ${ }^{\circledR} \mathrm{WF}$.

$\varepsilon$-Caprolactone ( $\varepsilon$-CL, 97\%) was distilled under vacuum before use. Tin (II) 2-ethylhexanoate ( $\mathrm{Sn}(\mathrm{oct})_{2}$, 98\%), $N, N$-dimethylbenzylamine (BDMA, $>99 \%$ ) and methyl hexahydrophthalic anhydride (MHHPA) were used without further purification. All these chemicals were purchased from Sigma-Aldrich (St. Louis, MO, USA). For the end-capping process by acetylation, extra pure acetic anhydride was used and purchased from Scharlau (Sentmenat, Spain). Triethyl amine (TEA) and $N, N$-dimethylamino pyridine (DMAP) were purchased from Fluka (Sentmenat, Spain). Chloroform $\left(\mathrm{CHCl}_{3}\right)$ was dried under $\mathrm{CaCl}_{2}$ and distilled before use. Solvents were purchased from Scharlab (Sentmenat, Spain).

Diglycidylether of bisphenol A (DGEBA) with an epoxy equivalent of $187 \mathrm{~g} / \mathrm{eq}$ (Epikote 828, Hexion Speciality Chemicals B.V. Louvain, Belgium) was dried for 4 hours at $40^{\circ} \mathrm{C}$ under vacuum before use.

\subsection{Synthesis of \\ poly(ethyleneimine)-poly(e-caprolactone) end-capped multiarm stars (PEIX)}

In the acronyms for both types of stars (PEIX), X accounts for the data sheet molecular weight times $10^{-2}$ and take the values of 8 and 250 for Lupasol ${ }^{\circledR} \mathrm{FG}$ and Lupasol ${ }^{\circledR} \mathrm{WF}$, respectively.

The hydroxyl terminated star polymers were synthesized by ring-opening polymerization of $\varepsilon$-capro- lactone from a hyperbranched poly(ethyleneimine) core in bulk at $130^{\circ} \mathrm{C}$. The acetylation to obtain PEIX was performed with acetic anhydride at room temperature overnight in the presence of TEA and a catalytic amount of DMAP in $\mathrm{CHCl}_{3}$ solution as previously described $[17,20]$. Figure 1 depicts the synthetic procedure applied in the preparation of the stars.

For both PEIX star polymers ${ }^{1} \mathrm{H}$ NMR $(400 \mathrm{MHz}$, $\mathrm{CDCl}_{3}, \delta$ in ppm): $4.08\left(-\mathrm{C}_{2}-\mathrm{OCO}-\right), 2.32$ (-NHCO- $\left.\underline{\mathrm{CH}}_{2}-,-\mathrm{CH}_{2}-\mathrm{COO}\right), 1.92\left(\mathrm{OCO}-\mathrm{CH}_{3}\right)$, $1.70-1.30$ ( $-\underline{\mathrm{CH}}_{2}-, \mathrm{CL}$ chain) and 3.5-1.5 (PEI core).

The structural data of the stars prepared determined by ${ }^{1} \mathrm{H}$ NMR and values in data sheet were as follows:

PEI8: polymerization degree of arms is 11.8. Fraction of unmodified primary/secondary amines of 0.15. $T_{\mathrm{g}}=-54^{\circ} \mathrm{C}, T_{\mathrm{m}}=58^{\circ} \mathrm{C}, \Delta h_{\mathrm{m}}=96 \mathrm{~J} / \mathrm{g}, T_{\max }=$ $390^{\circ} \mathrm{C}$ (temperature of the maximum rate of weight loss calculated by TGA).

PEI250: polymerization degree of arms is 13.5. Fraction of unmodified primary/secondary amines of 0.26. $T_{\mathrm{g}}=-59^{\circ} \mathrm{C}, T_{\mathrm{m}}=50^{\circ} \mathrm{C}, \Delta h_{\mathrm{m}}=75 \mathrm{~J} / \mathrm{g}, T_{\max }=$ $390^{\circ} \mathrm{C}$.

\subsection{Preparation of curing formulations}

Mixtures containing MHHPA and the selected proportion of the star polymer were heated mildly until the modifier was dissolved and the solution became clear. The mixture was then cooled down to room temperature and added to the corresponding amount of DGEBA and catalyst. Finally, samples were carefully stirred and degassed under vacuum $\left(\right.$ at $40^{\circ} \mathrm{C}$ ) during $15 \mathrm{~min}$ to prevent the appearance of bubbles during curing. The catalyst, BDMA, was used at a concentration of $1 \mathrm{phr}$ (1 part of catalyst per hundred parts of DGEBA/MHHPA mixture). The modifier was added at concentrations of 5, 10 and $20 \%$ with

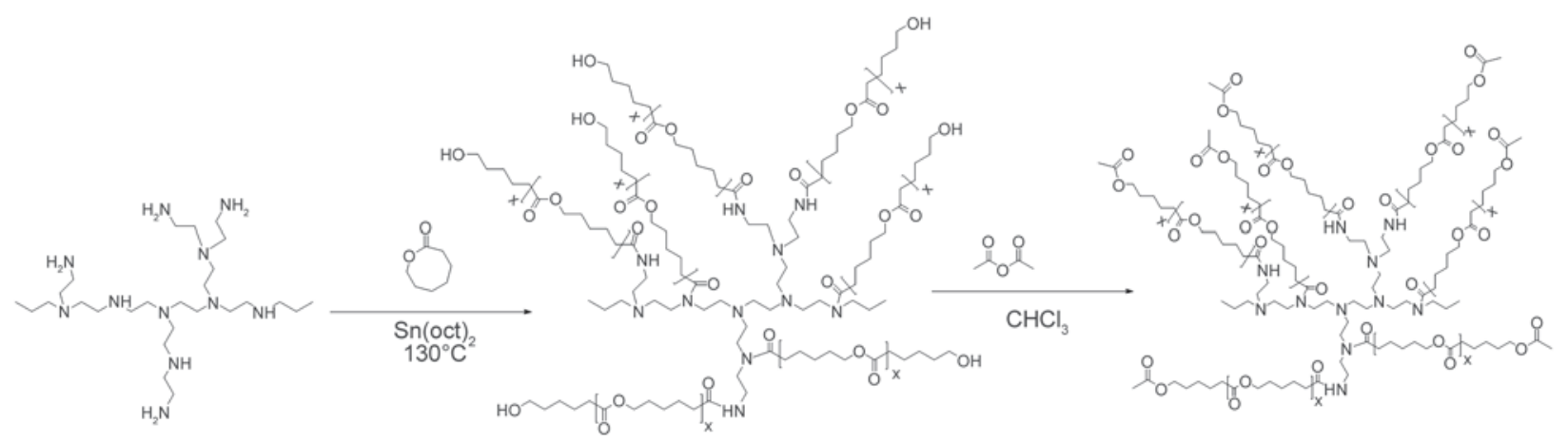

Figure 1. Synthetic procedure for the preparation of the multiarm stars PEI8 and PEI250 
Table 1. Notation and composition of the neat and modified formulations in weight percentage [wt $\%$ ] and in equivalents per gram of mixture. The weight percentage of the star polymer is indicated in formulation.

\begin{tabular}{|l|c|c|c|c|c|c|c|}
\hline \multirow{2}{*}{ Formulation } & \multicolumn{2}{|c|}{ DGEBA } & \multicolumn{2}{c|}{ MHHPA } & \multicolumn{2}{c|}{ BDMA } & NH from SP \\
\cline { 2 - 8 } & {$[\mathbf{w t} \% \mathbf{0}$} & {$[\mathbf{e q} / \mathbf{g}]$} & {$[\mathbf{w t} \%]$} & {$[\mathbf{e q} / \mathbf{g}]$} & {$[\mathbf{w t} \%]$} & {$[\mathbf{e q} / \mathbf{g}]$} & {$[\mathbf{e q} / \mathbf{g}]$} \\
\hline Neat & 52.1 & $2.79 \cdot 10^{-3}$ & 46.9 & $2.79 \cdot 10^{-3}$ & 0.99 & $7.32 \cdot 10^{-5}$ & 0 \\
\hline $5 \%$ PEI8 & 49.6 & $2.65 \cdot 10^{-3}$ & 44.7 & $2.65 \cdot 10^{-3}$ & 0.94 & $6.97 \cdot 10^{-5}$ & $3.95 \cdot 10^{-6}$ \\
\hline $10 \%$ PEI8 & 47.4 & $2.53 \cdot 10^{-3}$ & 42.6 & $2.53 \cdot 10^{-3}$ & 0.90 & $6.66 \cdot 10^{-5}$ & $7.54 \cdot 10^{-6}$ \\
\hline $20 \%$ PEI8 & 43.4 & $2.32 \cdot 10^{-3}$ & 39.1 & $2.32 \cdot 10^{-3}$ & 0.83 & $6.10 \cdot 10^{-5}$ & $1.38 \cdot 10^{-5}$ \\
\hline $5 \%$ PEI250 & 49.6 & $2.65 \cdot 10^{-3}$ & 44.7 & $2.65 \cdot 10^{-3}$ & 0.94 & $6.97 \cdot 10^{-5}$ & $1.00 \cdot 10^{-5}$ \\
\hline $10 \%$ PEI250 & 47.4 & $2.53 \cdot 10^{-3}$ & 42.6 & $2.53 \cdot 10^{-3}$ & 0.90 & $6.66 \cdot 10^{-5}$ & $1.92 \cdot 10^{-5}$ \\
\hline $20 \%$ PEI250 & 43.4 & $2.32 \cdot 10^{-3}$ & 39.1 & $2.32 \cdot 10^{-3}$ & 0.83 & $6.10 \cdot 10^{-5}$ & $3.51 \cdot 10^{-5}$ \\
\hline
\end{tabular}

respect to DGEBA/MHHPA/BDMA mixture. Table 1 collects the notation and composition of the different formulations studied.

Fully cured samples for DMA, TMA, TGA, DSC, impact and SEM assays were prepared by isothermal curing in oven at $100^{\circ} \mathrm{C}$ for $2 \mathrm{~h}$ followed by a postcuring at $180^{\circ} \mathrm{C}$ for one hour.

\subsection{NMR Spectroscopy}

${ }^{1} \mathrm{H}$ NMR and ${ }^{13} \mathrm{C}$ NMR measurements were carried out at 400 and 100.6 MHz, respectively, in a Varian Gemini 400 spectrometer (Palo Alto, USA). $\mathrm{CDCl}_{3}$ was used as solvent. For internal calibration the solvent signals were used: $\delta\left({ }^{13} \mathrm{C}\right)=77.16 \mathrm{ppm}$ and $\delta\left({ }^{1} \mathrm{H}\right)=7.26 \mathrm{ppm}$ for $\mathrm{CDCl}_{3}$.

\subsection{Calorimetric measurements (DSC)}

Calorimetric analyses were carried out on a Mettler DSC-822e thermal analyser (Greifensee, Switzerland). The calorimeter was calibrated using an indium standard (heat flow calibration) and an indium-zinc standard (temperature calibration).

Samples of approximately $10 \mathrm{mg}$ were placed in aluminium pans with pierced lids and cured non-isothermally from 0 to $300^{\circ} \mathrm{C}$ at heating rates of $2,5,10$ and $15^{\circ} \mathrm{C} / \mathrm{min}$, under nitrogen atmosphere, to determine the reaction heat associated with the complete conversion of all reactive groups and study the curing kinetics. In a non-isothermal curing process, the degree of conversion by DSC was calculated according to Equation (1):

$\alpha=\frac{\Delta h_{\mathrm{T}}}{\Delta h_{\mathrm{dyn}}}$

where $\Delta h_{\mathrm{T}}$ is the heat released up to a temperature $T$, obtained by integration of the calorimetric signal up to this temperature, and $\Delta h_{\mathrm{dyn}}$ is the total reaction heat associated with the complete conversion of all reactive groups. The reaction rate $\mathrm{d} \alpha / \mathrm{d} t$ was calculated as the first derivative of the conversion with respect to time.

The glass transition temperatures $\left(T_{\mathrm{g}_{\infty} \mathrm{S}}\right)$ of the obtained thermosets, uncured materials and star polymers were determined by means of a scan at $10^{\circ} \mathrm{C} / \mathrm{min}$ under nitrogen atmosphere, as the temperature of the half-way point of the jump in the heat capacity when the material changed from glassy to the rubbery state under $\mathrm{N}_{2}$ atmosphere and the error is estimated to be approximately $\pm 1^{\circ} \mathrm{C}$.

In order to predict the theoretical glass transition temperature of the formulations, Fox equation (Equation (2)) was used:

$\frac{1}{T}=\frac{w}{T_{\mathrm{g}, \mathrm{SP}}}+\frac{1-w}{T_{\mathrm{g}, \text { matrix }}}$

where $T_{\mathrm{g}, \mathrm{SP}}$ and $T_{\mathrm{g} \text {,matrix }}$ are the glass transition temperatures of the star polymer and neat epoxy/anhydride matrix respectively and $w$ is the weight fraction of star polymer in the formulation.

\subsection{Curing kinetics (DSC)}

The linear integral isoconversional, model-free method of Kissinger-Akahira-Sunose (KAS) was used for the determination of the activation energy based on the non-isothermal curing curves, as shown by Equation (3):

$\ln \left(\frac{\beta}{T^{2}}\right)=\ln \left(\frac{A \cdot R}{g(\alpha) \cdot E}\right)-\frac{E}{R T}$

$\beta$ is the heating rate, $T$ the temperature, $E$ the activation energy, $A$ the pre-exponential factor, $R$ the gas constant, and $g(\alpha)$ the integral conversion function. For each conversion degree, the representation of $\ln \left(\beta / T^{2}\right)$ versus $1 / T$ produces a straight line and makes it possible to determine $E$ and $\ln [A \cdot R /(g(\alpha) \cdot E)]$ from the slope and the intercept without knowing the kinetic model. 
Isoconversional isothermal curing times, $t$, were estimated taking the non-isothermal data $\ln [A \cdot R /(g(\alpha) \cdot E)]$ and $E$, determined from Equation (3), and applying the rate equation integrated in isothermal conditions, as shown by Equation (4):

$\ln t=\ln \left(\frac{g(\alpha)}{A}\right)+\frac{E}{R T}$

Assuming that the approximation given by expression (3) is valid, we can determine the kinetic model that best describes the curing process by rearranging expression (3) as shown in Equation (5):

$\ln \left(\frac{g(\alpha) \cdot \beta}{T^{2}}\right)=\ln \left(\frac{A \cdot R}{E}\right)-\frac{E}{R T}$

which is the basis for the composite integral method for the determination of the kinetic model. Given that the curing of epoxy-anhydride can be satisfactory modelled using autocatalytic-like models with an overall reaction order around 2, we have fitted using Equation (5) the experimental data to autocatalytic kinetic models with $n+m=2$, where $n$ and $m$ are the order of reaction.

The results of the kinetics analysis were used to model the curing and to determine the optimum curing times to achieve fully cured thermosets. In addition, isothermal curing times determined by simulation of non-isothermal kinetic data (Equations (3) and (4)) were compared with experimental isothermal curing times obtained by means of FTIR experiments.

Details of the kinetic methodology used can be found in previous works [21, 22].

\subsection{FTIR spectroscopy}

A Bruker Vertex FTIR spectrometer (Ettlingen, Germany) equipped with an attenuated-total-reflectance accessory with a diamond crystal (Golden Gate heated single-reflection diamond ATR, SpecacTeknokroma, Sant Cugat del Vallés, Spain) was used to monitor the curing process. Spectra were acquired in the mid-infrared region (spectral range of 600$4000 \mathrm{~cm}^{-1}$ ) with a resolution of $4 \mathrm{~cm}^{-1} .20$ scans were averaged for each spectrum. The evolution of the functional groups was monitored during isothermal curing at $100^{\circ} \mathrm{C}$, taking the band at $1508 \mathrm{~cm}^{-1}$, attributed to the DGEBA aromatic rings, as a reference. The conversion was determined by the Lambert-Beer law from the normalized change of absorbance at $1732 \mathrm{~cm}^{-1}$ (formation ester groups) and at
$1860+1785 \mathrm{~cm}^{-1}$ (disappearance of anhydride group) as explained in a previous work [22].

\subsection{Thermomechanical analysis (TMA)}

A thermo-mechanical analyzer Mettler thermomechanical analysis SDTA840 (Greifensee, Switzerland) was used to determine the conversion at the gel point and the thermal expansion coefficients.

A silanized glass fiber disc about $5 \mathrm{~mm}$ in diameter was impregnated with the liquid formulation and sandwiched between two aluminium discs. The sample was heated up from 40 to $200^{\circ} \mathrm{C}$ at $2^{\circ} \mathrm{C} / \mathrm{min}$ and subjected to an oscillatory force from 0.005 to $0.01 \mathrm{~N}$ with an oscillation frequency of $0.083 \mathrm{~Hz}$. The gel point temperature was taken as the onset in the decrease of the oscillation amplitude measured by the probe. The conversion at the gel point was determined from the gel point temperature and a dynamic curing experiment in the DSC at $2^{\circ} \mathrm{C} / \mathrm{min}$.

Cured samples $\left(1.5 \times 8 \times 8 \mathrm{~mm}^{3}\right)$ were supported by two silica discs and heated at $5^{\circ} \mathrm{C} / \mathrm{min}$ from 30 up to $150^{\circ} \mathrm{C}$ by application of a force of $0.02 \mathrm{~N}$. Two heating scans were performed, the first one to erase the thermal history and the second one to determine the thermal expansion coefficients (CTEs), below and above the $T_{\mathrm{g}}$, calculated according to Equation (6):

$$
C T E=\frac{1}{L_{0}} \cdot \frac{\mathrm{d} L}{\mathrm{~d} T}=\frac{1}{L_{0}} \cdot \frac{\frac{\mathrm{d} L}{\mathrm{~d} t}}{\frac{\mathrm{d} T}{\mathrm{~d} t}}
$$

where, $L$ is the thickness of the sample, $L_{0}$ the initial length, $t$ the time, $T$ the temperature and $\mathrm{d} T / \mathrm{d} t$ the heating rate.

\subsection{Dynamic mechanical analysis (DMA)}

DMA was carried out with a TA Instruments DMA Q800 (New Castle, DE, USA). Three point bending of $10 \mathrm{~mm}$ at $1 \mathrm{~Hz}$ and $0.05 \%$ strain was performed at $3^{\circ} \mathrm{C} / \mathrm{min}$ from -150 to $250^{\circ} \mathrm{C}$ on prismatic rectangular samples (ca. $2 \times 12 \times 20 \mathrm{~mm}^{3}$ ).

\subsection{Thermal stress}

The thermal stress caused by the variation of the temperature, $\sigma_{\text {th }}$, in a bi-layer strip (epoxy-anhydride coating/steel substrate) was determined from the radius of curvature, $R$, in the assumptions of the simple beam theory and from the free body analysis of strains in the two layers. The calculation was made 
taking account the dependence on the geometrical parameters and properties of the sample and substrate, according to Benabdi and Roche methodology [23], see Equations (7) and (8):

$$
\begin{aligned}
& \frac{1}{R}=\frac{6(1+\beta)^{2}\left(S F T-T_{\mathrm{amb}}\right)\left(C T E_{\mathrm{c}}-C T E_{\mathrm{s}}\right)}{\left(t_{\mathrm{c}}+t_{\mathrm{s}}\right)\left[3(1+\beta)^{2}(1+\alpha \beta)\left(\beta^{2}+\frac{1}{\alpha \beta}\right)\right]} \\
& \sigma_{\mathrm{th}}=\frac{1}{R} \cdot \frac{E_{\mathrm{s}} \cdot t_{\mathrm{s}}}{6}\left[\frac{1}{\beta(\beta+1)}\left(\alpha \beta^{3}+1\right)+3 \alpha \beta\right]
\end{aligned}
$$

where the subscripts $c$ and $s$ mean coating and substrate respectively, $t$ is the thickness, $E$ the elastic modulus, $\alpha=E_{\mathrm{c}} / E_{\mathrm{s}}, \beta=t_{\mathrm{c}} / t_{\mathrm{s}}, S F T$ is the stress free temperature taken as the transition glass transition temperature determined by TMA and $T_{\mathrm{amb}}$ is the ambient temperature taken as $40^{\circ} \mathrm{C}$.

In this study a stainless steel, with an elastic modulus of $180053 \mathrm{MPa}$ and thermal expansion coefficient of $16 \cdot 10^{-60} \mathrm{C}^{-1}$, was selected as the substrate and the thickness of the steel substrate and the epoxy/ anhydride coating was respectively 0.1 and $0.4 \mathrm{~mm}$. The elastic modulus of epoxy/anhydride sample was determined by DMA.

\subsection{Thermogravimetric analysis (TGA)}

Thermogravimetric analysis was carried out with a Mettler TGA/SDTA 851e/LF/1100 thermobalance (Greifensee, Switzerland). Samples with an approximate mass of $10 \mathrm{mg}$ were degraded between 30 and $800^{\circ} \mathrm{C}$ at a heating rate of $10^{\circ} \mathrm{C} / \mathrm{min}$ in a nitrogen atmosphere $(50 \mathrm{~cm} 3 / \mathrm{min}$ measured in normal conditions).

\subsection{Impact resistance}

The impact test was performed at room temperature by means of an Zwick 5110 impact tester (Ulm, Germany) according to ASTM D 4508-10 (2010) using rectangular samples $\left(2 \times 12 \times 25 \mathrm{~mm}^{3}\right)$. The pendulum employed had a kinetic energy of $0.5 \mathrm{~J}$. For each material, nine determinations were made. The impact strength $(I S)$ was calculated from the energy absorbed by the sample upon fracture according to Equation (9):

$I S=\frac{E-E_{0}}{S}$

where $E$ and $E_{0}$ are the energy loss of the pendulum with and without sample respectively, and $S$ is the cross-section of the samples.

\subsection{Electron microscopy analysis (SEM)}

The fracture surface of the samples, previously fractured by impact at room temperature, was coated with a conductive gold layer and then examined with a Jeol JSM 6400 SEM (JEOL Ltd., Tokyo, Japan) with a resolution of $3.5 \mathrm{~nm}$ and different magnifications $(100,50010000$ and 50000).

\section{Results and discussion \\ 3.1. Synthesis and characterization of multiarm stars}

The synthesis of the multiarm stars was performed as previously described in two different papers, one of them describing the growing of the poly ( $\varepsilon$-caprolactone) arms from the PEI core and the other to the blocking of hydroxyl end-groups by reaction with acetic anhydride $[17,20]$. The length of the arms can be adjusted, in principle, from the amount of $\varepsilon-\mathrm{CL}$ per reactive group in the core $\left(\mathrm{NH}\right.$ and $\left.\mathrm{NH}_{2}\right)$. In this paper, PEI cores of 800 and $25000 \mathrm{~g} / \mathrm{mol}$ of massaverage molecular weight were employed.

The multiarm star molecules where characterized by ${ }^{1} \mathrm{H}$ NMR spectroscopy as done in the previous works $[17,20]$. It could be seen that the increase in the molecular weight of the core did not change significantly the ${ }^{1} \mathrm{H}$ NMR spectrum. From the spectra of the hydroxyl-ended stars we could determine the degree of polymerization of the arms. However, in both cases the arms were longer $(D P=11.8$ and 13.5) than expected $(D P=10)$ and the difference was higher for the larger core. Since all the $\varepsilon$-CL reacts, the higher polymerization degree of the arms calculated from the spectra led us to the conclusion that part of the $\mathrm{NH}-$ and $\mathrm{NH}_{2}$ groups could not initiate the growth of an arm. From these values we estimated a degree of modification of 0.85 for the PEI8 core and of 0.74 for the PEI 250 core. The effect of the core size is noteworthy, as the degree of modification of the PEI250 core is significantly lower. The hydrogen bond interactions and the steric hindrance could be the responsible for these differences. Although the evaluation of the modification achieved in terminal and linear units could not be accomplished, linear units seem to be less reactive because of the lower nucleophilicity of secondary amines and the more internal position of these units in the PEI structure. Moreover, intra-molecular hydrogen bonding in PEI may make difficult the penetration of $\varepsilon$-CL into the core structure and the subsequent polymerization reaction. 
The acetylation of the hydroxyl groups at the end of the arms was performed as described and the spectra obtained were similar to the ones published before [20]. The complete disappearance of $-\mathrm{CH}_{2} \mathrm{OH}$ signals showed that all hydroxyl groups were blocked. The intensity of the methyl signals (at $1.92 \mathrm{ppm}$ ) allowed us to determine that unreacted $\mathrm{NH}$ groups were still in PEI8 and PEI250 structures.

By using linear standards the molecular weight of star polymers are usually underestimated by GPC and this method does not rend accurate molecular weights. However, the GPC analysis did not produce signals at low molecular weight, meaning that no detectable poly( $\varepsilon$-caprolactone) homopolymer was formed during the ring-opening polymerization. In addition, the shape of the curves was unimodal in both PEI8 and PEI250, due to the living characteristics of the $\varepsilon$-CL polymerization.

\subsection{Study of the curing and thermal properties of DGEBA/MHHPA/PEIX mixtures}

The presence of hydroxyl groups and tertiary amines in epoxy-anhydride formulations, leads to a complex competitive mechanism consisting of polycondensation, initiated by hydroxyl groups, and ring opening polymerization, initiated by tertiary amine $[19,24]$. Moreover the existence of secondary and/or primary amines in the reaction medium may also lead to a polycondensation between these groups and epoxy resin or even anhydrides and the concomitant appearance of new tertiary amines or amides. In previous works we reported the use of hyperbranched poly(ethyleneimine)s as crosslinking agents in epoxy formulations $[25,26]$, reacting by an epoxy-amine condensation mechanism and getting thus incorporated into the network structure of the thermoset. The curing kinetics was slowed down by their lower mobility in comparison with smaller amines and they led to more densely crosslinked materials due to the presence of internal branching points in the hyperbranched polymer structure. However, the total number of reactive amino groups introduced in the formulation is very small taking into account the elevated molecular weight of the stars polymers, and the effect would be difficult to quantify. It should be also noticed that not all the amine groups would be able to react because of steric hindrance or topology restrictions.

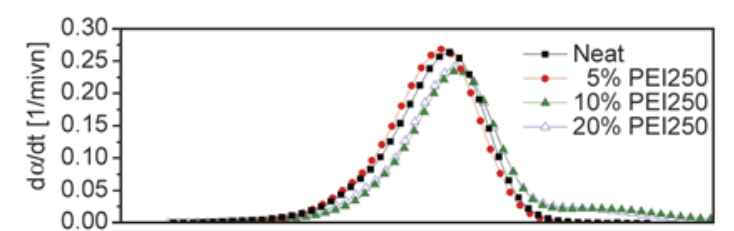

$$
\text { a) }
$$

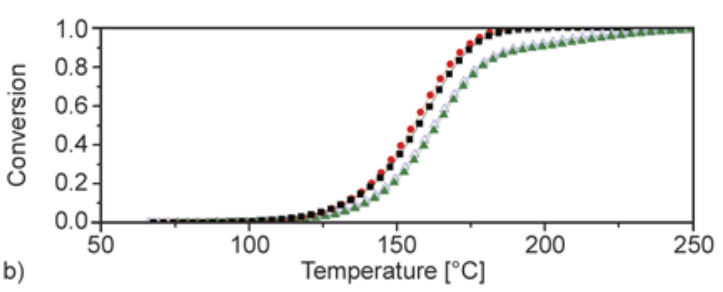

Figure 2. Reaction rate $\mathrm{d} \alpha / \mathrm{d} t(\mathrm{a})$ and degree of conversion (b) against temperature of neat and PEI250 formulations at $10^{\circ} \mathrm{C} / \mathrm{min}$

Figure 2 shows the plots of degree of conversion and reaction rate against temperature recorded at $10^{\circ} \mathrm{C} / \mathrm{min}$ of neat formulation and formulations containing different amounts of PEI250. Calorimetric curves for neat and 5\% showed a unimodal shape, which indicates that, the different curing mechanism takes place at the same time or that one of them predominates, in particular the epoxy-anhydride alternating copolymerization mechanism, due to the presence of BDMA. Formulations containing 10 and $20 \%$ of PEI 250 show a secondary process at conversions above 0.8 . Because epoxy-amine condensation may take place at a relatively low temperature $[25,26]$ this process, at high temperature and slow rate, could be related with the non-catalytic epoxy/ anhydride curing mechanism or epoxy homopolymerization, although this is generally observed in anhydride-deficient formulations [27].

In the presence of a small amount of star polymer the curing is slightly accelerated possibly due to the additional tertiary amines coming from the modifier. When a higher amount of modifier is used (10 and $20 \%$ ) the reaction rate decrease and the conversion-temperature curves shift at higher temperatures (Figure 2). In these last cases the higher viscosity of the formulations, the lower mobility of the reactive species and the lower content of epoxides may contribute to decelerate the curing rate of the epoxy/ anhydride/PEIX formulations. Although the differences between formulations are not large, the relative influence of the discussed parameters can lead to acceleration or deceleration of the curing.

When PEI8 was used as modifier a similar trend was observed (not shown), although both effects, accel- 


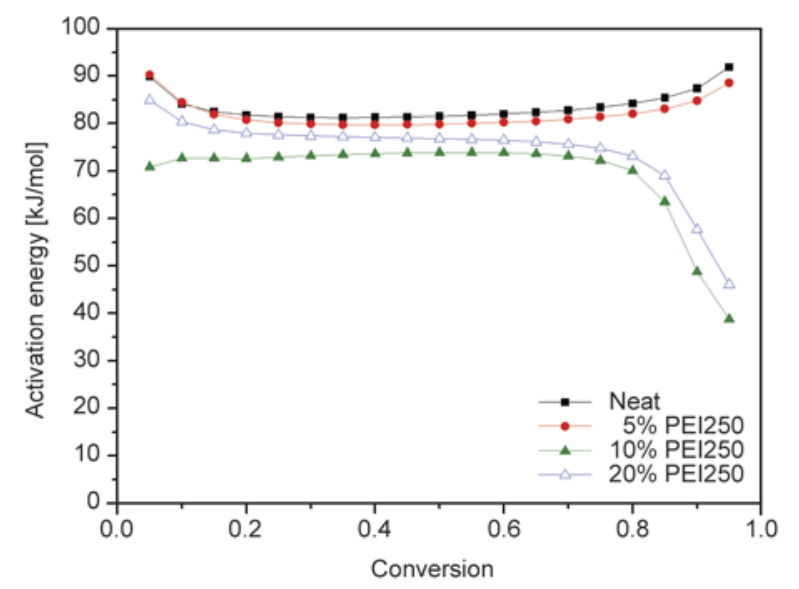

Figure 3. Activation energy during curing of neat and PEI250 formulations obtained by using the KissingerAkahira-Sunose method

eration at low modifier content and deceleration at high modifier content, take place to a lesser extent. This result can be rationalized on the basis of the lower tertiary amine content and viscosity of PEI8 than PEI250.

The nonisothermal curing kinetics was analyzed using the isoconversional KAS methodology (Equation (3)). Figure 3 shows that $E$ remains constant during the entire range of conversions for neat and 5\% formulations, whereas for 10 and $20 \% E$ is maintained constant up to a conversion of 0.8 , to decrease sharply between 0.8 and 1 . This result is consistent with the existence of two curing mechanisms, activated at different temperatures, in modifier-rich formulations (Figure 2).

As described in the experimental section, model fitting was performed using suitable phenomenological model, autocatalytic model with $n+m=2$ [22, 24], which may generally describe the autocatalytic behaviour of the catalyzed epoxy-anhydride curing. Non-isothermal data at different heating rates were simultaneously fitted by linear regression (Equation (5)), in the conversion range $0.1-0.8$, where activation energy is nearly constant for all formulations.

Table 2 summarizes the results of the linear fitting and other kinetic parameters. The linear regression coefficients get close to one and the similarity between fitted and isoconversional activation energies evidence the quality of the fitting and the suitability of the kinetic model chosen. All formulations show similar kinetic parameters, an indication of the fact that the curing mechanism is not significantly affected by the presence of the star polymer modifier. The values of $\mathrm{d} \alpha / \mathrm{d} t$ and $k$, calculated using Arrhenius equation and the kinetic parameters, activation energy and pre-exponential factor obtained by adjustment, agree with the reactivity of the different formulations and with the experimental calorimetric curves (Figure 2). On increasing the content of star polymer up to $5 \%$, the curing accelerates $(k$ and $\mathrm{d} \alpha / \mathrm{d} t$ increase), but gradually decelerates ( $k$ and $\mathrm{d} \alpha / \mathrm{d} t$ decrease) at higher modifier contents. The kinetic effects of the modifier are more relevant when PEI250 is used, showing greater differences between the values of $k$ and $\mathrm{d} \alpha / \mathrm{d} t$ and those of the neat formulation.

The curing kinetics of all formulations were studied with FTIR spectroscopy at $100^{\circ} \mathrm{C}$ in order to identify the main reactions taking place during curing and compared with the curing kinetics obtained by nonisothermal procedure. Figure 4 shows FTIR spectra recorded during isothermal curing of neat formulation at $100^{\circ} \mathrm{C}$. The general features of the epoxyanhydride curing reaction can be observed: the decrease of the anhydride groups (bands at 1780 and $1860 \mathrm{~cm}^{-1}$ ) that react giving rise to ester groups $\left(1735 \mathrm{~cm}^{-1}\right)$. The disappearance of epoxy groups was also observed but not quantified because of the difficulty to separate its contribution from the different overlapping signals in the region around $910 \mathrm{~cm}^{-1}$.

Table 2. Kinetic parameters of curing process

\begin{tabular}{|c|c|c|c|c|c|c|c|c|}
\hline Formulation & $\begin{array}{c}\mathbf{E}^{\mathrm{a}} \\
{[\mathrm{kJ} / \mathrm{mol}]}\end{array}$ & $\begin{array}{c}\ln \mathbf{A}^{\mathbf{a}} \\
{\left[\min ^{-1}\right]}\end{array}$ & $\mathbf{n}^{\mathbf{a}}$ & $\mathbf{m}^{\mathrm{a}}$ & $\mathbf{r}^{\mathbf{a}}$ & $\begin{array}{l}\mathrm{k}_{150^{\circ}} \mathrm{C}^{\mathrm{b}} \\
{\left[\mathrm{min}^{-1}\right]}\end{array}$ & $\begin{array}{c}(\mathrm{d} \alpha / \mathrm{dt})_{0.5^{\mathrm{c}}} \\
{\left[\mathrm{min}^{-1}\right]}\end{array}$ & $\mathbf{E}_{\text {iso }}{ }^{d}$ \\
\hline Neat & 82 & 22.92 & 1.58 & 0.42 & 0.999 & 0.66 & 0.165 & 83 \\
\hline $5 \%$ PEI8 & 76 & 21.39 & 1.53 & 0.47 & 0.999 & 0.69 & 0.174 & 77 \\
\hline $10 \%$ PEI 8 & 77 & 21.42 & 1.54 & 0.46 & 0.999 & 0.65 & 0.161 & 77 \\
\hline $20 \%$ PEI 8 & 67 & 18.48 & 1.53 & 0.47 & 0.999 & 0.50 & 0.125 & 69 \\
\hline $5 \%$ PEI 250 & 81 & 22.64 & 1.55 & 0.45 & 0.999 & 0.75 & 0.187 & 82 \\
\hline $10 \%$ PEI 250 & 70 & 18.95 & 1.57 & 0.43 & 0.992 & 0.38 & 0.095 & 71 \\
\hline $20 \%$ PEI 250 & 75 & 20.95 & 1.57 & 0.43 & 0.999 & 0.45 & 0.113 & 75 \\
\hline
\end{tabular}

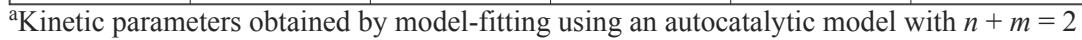

${ }^{b}$ Values of rate constant at $150^{\circ} \mathrm{C}$ using the Arrhenius equation and the parameters $E$ and $\ln \mathrm{A}$

${ }^{\mathrm{c}}$ Values of reaction rate at $150^{\circ} \mathrm{C}$ obtained using the equation rate $\mathrm{d} \alpha / \mathrm{d} t=k \cdot f(\alpha)=k \cdot(1-\alpha)^{\mathrm{n}} \cdot \alpha^{\mathrm{n}}$ at $50 \%$ conversion

${ }^{\mathrm{d}}$ Average isoconversional activation energy. 


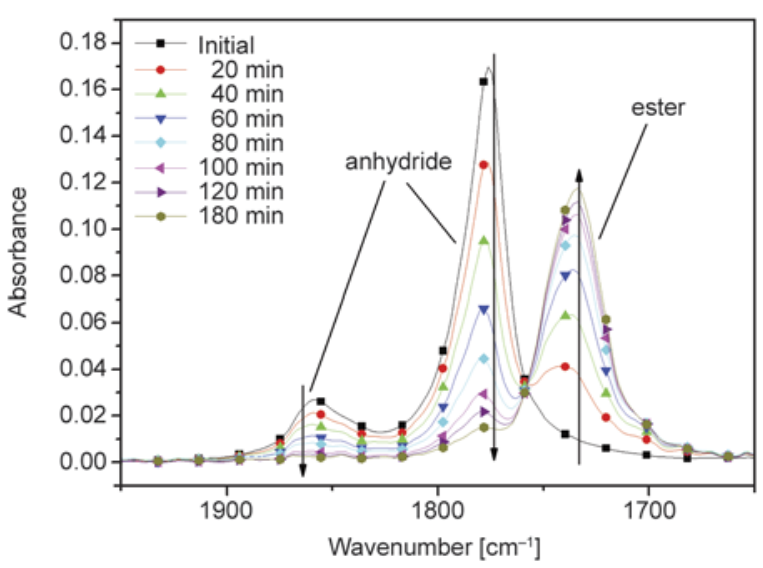

Figure 4. FTIR spectra recorded during curing of neat formulation at $100^{\circ} \mathrm{C}$

Figure 5 shows the evolution of ester and anhydride groups against time recorded during curing for the $10 \% \mathrm{PEI} 250$ formulation at $100^{\circ} \mathrm{C}$ in the spectrometer. It can be observed that the formation of ester and the disappearance of anhydride groups take place almost at the same time up to 0.6 of conversion, showing little discrepancies at higher conversion. This result agrees with the fact the curing mainly follows an alternating epoxy-anhydride mechanism catalyzed by tertiary amines. The inset in Figure 5 plots the ester conversion with respect to the anhydride conversion at $100^{\circ} \mathrm{C}$ for neat and all the PEI 250 formulations. It can be observed that the evolution of both groups follows the diagonal line, indicating again an alternating copolymerization mechanism. Figure 5 shows the conversion of epoxy groups determined by using Equation (4) from the non-isothermal isoconversional kinetic parameters obtained by DSC.

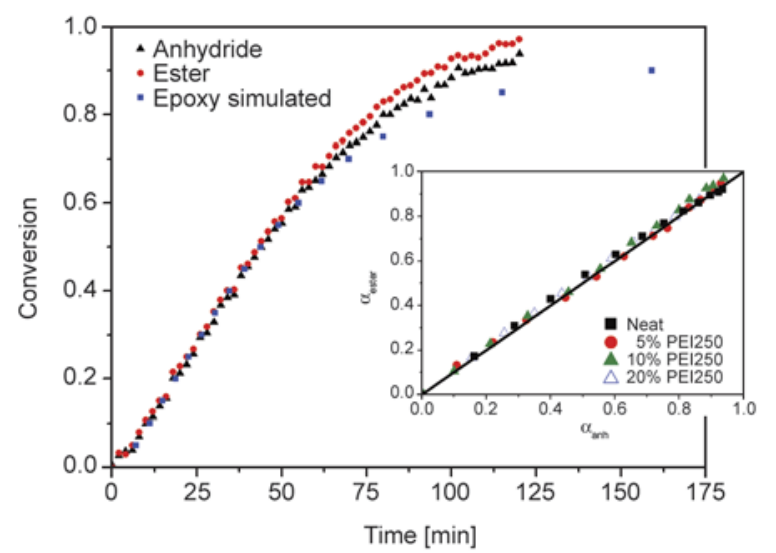

Figure 5. Conversion of the ester groups, $\alpha_{\text {ester }}$, and reacted anhydride, $\alpha_{\mathrm{anh}}$, during curing of $10 \%$ PEI250 formulation at $100^{\circ} \mathrm{C}$ in FTIR. Epoxy conversion simulated using non-isothermal isoconversional DSC data. Inset: conversion of the ester groups against reacted anhydride for neat and PEI250 formulations.
It can be observed that the conversions are similar to those obtained by FTIR. The slight differences between the evolutions of the different reactive species observed at high conversions can be related with the activation of a second curing mechanism that takes place during non-isothermal curing in DSC (Figure 5) at higher temperatures, uncatalyzed epoxy-anhydride reaction or epoxy homopolymerization, a process that is not activated during isothermal curing at moderate temperatures. FTIR and DSC simulation of PEI8 formulations showed similar trends than those observed for PEI250.

It can be concluded that curing of epoxy-anhydride formulations containing PEI8 and PEI250 proceeds mainly by anionic alternating copolymerization catalyzed by tertiary amines. Rocks et al. [28] studied the curing of epoxy-anhydride formulations catalyzed by tertiary amines by Raman spectroscopy and concluded that, in spite of the complexity of the curing mechanism, the overall curing profile corresponded to an alternating epoxy-anhydride copolymerization. However, epoxy-amine condensation may take place, thus permitting the covalent linkage between the modifier and the matrix. The quantification of this process is not possible, since it may take place to a very low extent. The other processes, occurring at higher temperatures, as observed by DSC, may not be relevant depending on the isothermal curing schedule selected in the processing.

Table 3 shows the experimental heats of polymerization, $\Delta h$, calculated as the average heat of the experiments at different heating rates. On increasing the proportion of modifier $\Delta h[\mathrm{~J} / \mathrm{g}]$ decreases due to the lower content of reactive epoxy and anhydride groups, whereas $\Delta h[\mathrm{~kJ} / \mathrm{ee}]$ remains almost constant and similar to the values reported for other similar epoxy systems [29]. FTIR spectra of both isothermal and non-isothermal cured samples showed that the absorbance bands of oxirane and anhydride groups disappeared completely. Moreover, no residual heat was observed after a second dynamic scan made up to $250^{\circ} \mathrm{C}$ to determine $T_{\mathrm{g}}$. These results indicate that all formulations reacted almost completely.

The $T_{\mathrm{g}}$ of the isothermally cured samples, determined by DSC, decreases progressively on increasing the proportion of star polymer in the formulation, but this decrease is more evident when PEI250 is used. The different flexibilities of both modifiers, the amount of physical entanglement and crosslinking density and the existence of separated phases of different size 
Table 3. Calorimetric data, $\alpha_{\text {gel }}$, thermal stability data and dynamomechanical properties of the formulation studied in this work

\begin{tabular}{|c|c|c|c|c|c|c|c|c|c|}
\hline Formulation & $\begin{array}{c}\Delta \mathbf{h}^{\mathbf{a}} \\
{[\mathbf{J} / \mathbf{g}]}\end{array}$ & $\begin{array}{c}\Delta \mathbf{h}^{\mathbf{b}} \\
{[\mathbf{k J} / \mathbf{e e}]}\end{array}$ & $\begin{array}{l}\mathbf{T}_{\mathbf{g} \infty} \mathbf{c} \\
{\left[{ }^{\circ} \mathbf{C}\right]}\end{array}$ & $\begin{array}{c}\mathbf{T}_{\mathbf{g} \infty, \mathbf{F o x}}{ }^{\mathbf{d}} \\
{\left[{ }^{\circ} \mathbf{C}\right]}\end{array}$ & $\alpha_{g e l}{ }^{e}$ & $\begin{array}{l}\mathbf{T}_{\max } \mathbf{f} \\
{\left[{ }^{\circ} \mathbf{C}\right]}\end{array}$ & $\begin{array}{c}\tan \delta^{g} \\
\text { peak } \\
{\left[{ }^{\circ} \mathrm{C}\right]}\end{array}$ & $\begin{array}{c}\tan \delta^{\mathrm{h}} \\
\text { FWHM } \\
{\left[{ }^{\circ} \mathrm{C}\right]}\end{array}$ & $\begin{array}{c}\mathbf{E}_{\mathbf{r}}{ }^{\mathbf{i}} \\
{[\mathrm{MPa}]}\end{array}$ \\
\hline Neat & 288 & 103 & 132 & 132 & 0.47 & 406 & 143 & 14 & 28 \\
\hline $5 \%$ PEI8 & 272 & 103 & 126 & 115 & 0.55 & 406 & 139 & 17 & 24 \\
\hline $10 \%$ PEI 8 & 258 & 103 & 118 & 99 & 0.49 & 405 & 130 & 25 & 20 \\
\hline $20 \%$ PEI 8 & 249 & 112 & 111 & 71 & 0.52 & 405 & 124 & 32 & 16 \\
\hline $5 \%$ PEI 250 & 257 & 97 & 118 & 115 & 0.45 & 405 & 127 & 16 & 23 \\
\hline $10 \%$ PEI 250 & 255 & 102 & 111 & 99 & 0.45 & 404 & 124 & 25 & 18 \\
\hline $20 \%$ PEI250 & 230 & 103 & 103 & 71 & 0.48 & 403 & 114 & 32 & 13 \\
\hline
\end{tabular}

${ }^{a}$ Enthalpies per gram of mixtures

${ }^{b}$ Enthalpies per equivalent of epoxy groups

${ }^{\mathrm{c}}$ Glass transition temperature after isothermal curing

${ }^{\mathrm{d}}$ Calculated glass transition temperature, using DSC data and Fox equation

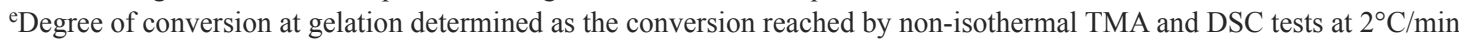

${ }^{\mathrm{f}}$ Temperature of the maximum rate of weight loss calculated by thermogravimetry

gTemperature of maximum of $\tan \delta$

${ }^{h}$ FWHM stands for full width at half maximum of $\tan \delta$

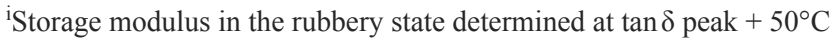

and structure could be responsible of this behaviour. In order to understand the effect of the star on the matrix, the Fox equation was applied to predict the $T_{\mathrm{g}}$ of the fully cured thermosets. Up to $5 \%$ of PEI 250 content, the thermosets have an experimental value of $T_{\mathrm{g}}$ similar to the predicted by this equation, whereas formulations containing 10 and $20 \%$ of both modifiers show experimental $T_{\mathrm{g}}$ 's significantly higher than the theoretical ones. These results could be explained by a phase separation of the star polymer due to the incompatibility produced during the curing reaction, which was further confirmed by electron microscopy.

The results of the gelation tests are summarized in Table 3. The conversion at the gelation point $\alpha_{\text {gel }}$ is only little affected by the addition of both star polymers, and in all cases the obtained values are within the range commonly observed for epoxy-anhydride systems, around $0.3-0.5$ [24, 30, 31]. This scattering of values can be explained not only by the differences and accuracy of the measuring techniques but from the presence of protic impurities or the occurrence of initiator regeneration reactions that tend to increase $\alpha_{\text {gel }}[30-32]$.

Figure 6 shows the thermogravimetric curves for neat and PEI250 formulations. It can be observed that the degradation takes place in only one step, indicating random breaking of bonds. Formulations containing PEI8 show similar TGA traces (not shown). The results of the thermogravimetric analysis of all formulations are summarized in Table 3. Although modified formulations contain $\mathrm{C}-\mathrm{N}$ bonds that are less stable than the $\mathrm{C}-\mathrm{C}$ bonds of the epoxy matrix,

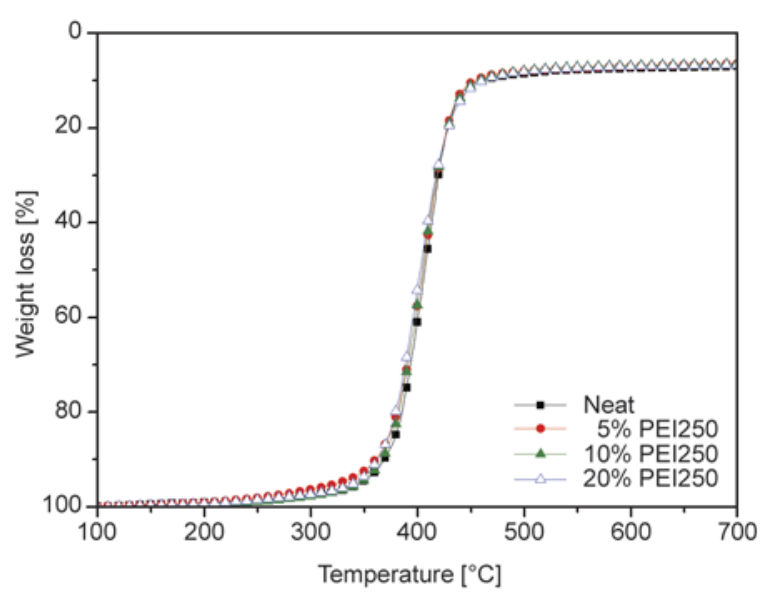

Figure 6. Thermogravimetric curves at $10^{\circ} \mathrm{C} / \mathrm{min}$ in nitrogen atmosphere of the neat and PEI250 formulations

all formulations show similar thermal stability $\left(T_{\max }\right)$. This is in agreement with previously reported results using poly( $\varepsilon$-caprolactone) modified polymers [17, 20]. This can be explained by the low proportion of hyperbranched core in the modifier structure (even lower in the formulation), the similar thermal stability of the ester bonds in the poly( $\varepsilon$-caprolactone) arms and the epoxy-anhydride polyester network structure, and the possible covalent linkage between the matrix and the modifier.

\subsection{Thermomechanical properties and thermal stress}

Table 3 collects the results of the DMA characterization of all the samples prepared. Figures 7 and 8 plot the evolution of $\tan \delta$ and storage modulus of PEI250 and PEI8 formulations, respectively. In 


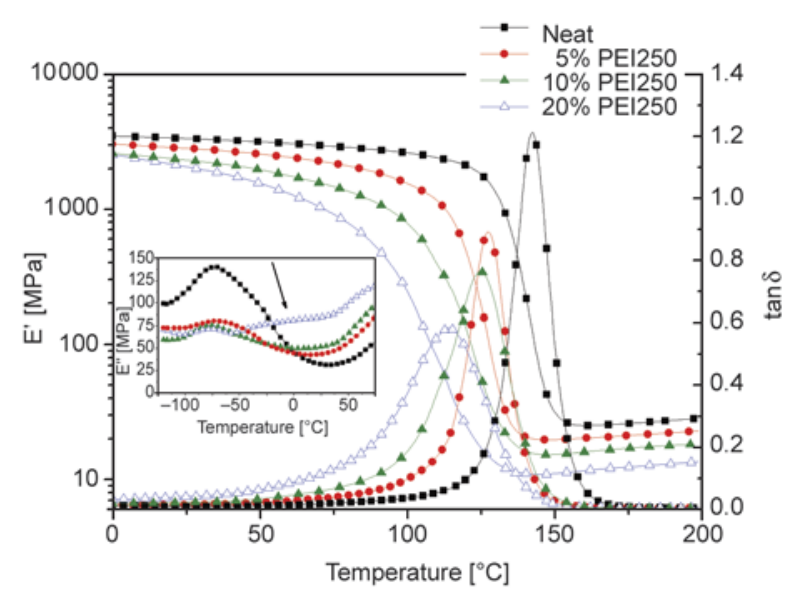

Figure 7. Storage modulus and $\tan \delta$ curve against temperature for neat and PEI250 modified materials. The inset shows a detail of loss modulus curves at low temperatures.

agreement with the calorimetric data, when the proportion of modifier increases, the network relaxation curves are shifted towards lower temperatures, indicating that $T_{\mathrm{g}}$ decreases on adding modifier, as seen with DSC. The effect is more remarkable in PEI250 formulations, probably due to an increase in the plasticization caused by the longer poly(e-caprolactone) arms or a decrease in the crosslinking density. It can also be observed that the $\alpha$ relaxations (related to the $T_{\mathrm{g}}$ ) of all formulations are unimodal, indicating that all thermosets have homogeneous network structures, but modifier-rich formulations show a more disperse network, as seen from the broader $\alpha$-relaxation and higher FWHM values. Meng and coworkers [33, 34] observed the contrary trend using hyperbranched polyethers as tougheners for epoxy/amine systems, but their materials showed a homogeneous morphology. Table 3

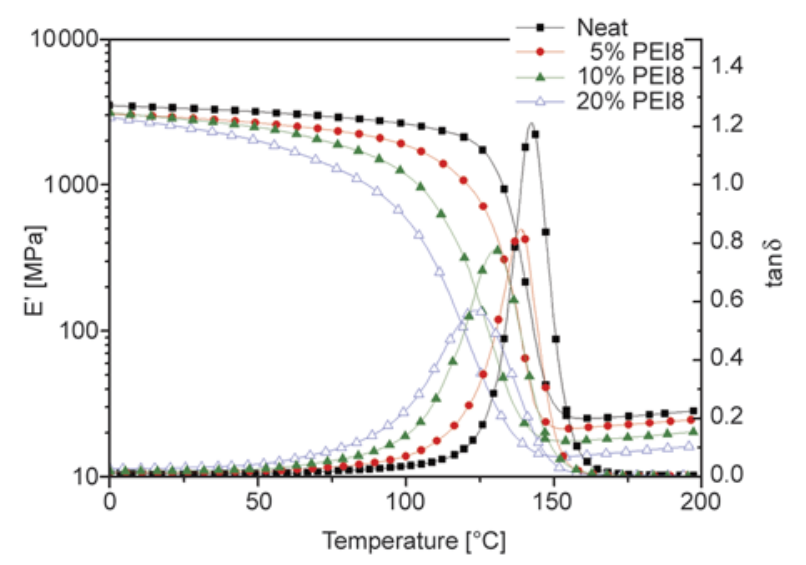

Figure 8. Storage modulus and $\tan \delta$ curve against temperature for neat and PEI8 modified materials and Figures 7 and 8 show a decrease in the rubbery modulus and in the height of $\alpha$-relaxation upon addition of the modifier. According to the rubber elasticity theory, the relaxed modulus is proportional to the crosslinking density, but deviations from the ideal network behaviour are likely to occur for a variety of reasons $[26,35,36]$. The decrease in rubbery modulus is not proportional to the modifier content, suggesting an additional decrease in the crosslinking density connected with the participation of the star polymer in the curing process.

The inset in Figure 7 shows a detail of loss modulus curves in the region of low temperature. It can be seen that the $\beta$-relaxation (attributed to glyceryl or diphenylpropane groups) decreases but it broadens on increasing the modifier content. This can be tentatively attributed to a new star polymer-rich phase formed during curing and to a restricted mobility of the matrix structure due to the additional bonding with star-polymer.

In order to determine the potential application of the prepared materials as coatings, the generation of thermal stress during cooling of neat and PEI250 and PEI8 formulations on steel as a rigid substrate were studied using the Benabdi and Roche methodology described in the experimental section [23]. In a previous work, we demonstrated that the intrinsic stress generated during curing of an epoxy system, due to rearrangement of molecular structure, and the thermal stress generated in the rubbery state, are much lower than the thermal stress generated on cooling down from the $T_{\mathrm{g}}$ to room temperature [14, $20]$, therefore in the present work we only calculate the thermal stress originated on cooling.

Table 4 collects the thermal stress values, $\sigma_{\text {th }}$, calculated using Equations (7) and (8) and the following experimental data of epoxy/anhydride/PEIX coating: $C T E_{\mathrm{c}}$ in the glassy state determined by TMA, elastic modulus determined by DMA at room temperature $\left(40^{\circ} \mathrm{C}\right), E_{\mathrm{c}}$, and stress free temperature, $S F T$, taken as the glass transition temperature determined by TMA. It can be observed as $\sigma_{\text {th }}$ decreases significantly on increasing the modifier content, due to a decreasing of some of these three parameters: $C T E_{\mathrm{c}}$, $E_{\mathrm{c}}$ and $S F T$. In general, $E_{\mathrm{c}}$ and $S F T$ regularly decrease on increasing PEIX content, according to the high flexibility and low crosslinking density of modified thermosets, whereas $C T E_{\mathrm{c}}$ does not follow a clear trend. While the $C T E_{\mathrm{c}}$ of PEI8 formulations hardly varies, $C T E_{\mathrm{c}}$ of PEI250 formulations 
Table 4. Thermal data of the materials and thermal stresses generated during cooling for the different formulations

\begin{tabular}{|l|c|c|c|c|c|r|}
\hline Formulation & $\begin{array}{c}\mathbf{E}_{\mathbf{c}}{ }^{\mathbf{a}} \\
{[\mathbf{M P a}]}\end{array}$ & $\boldsymbol{\alpha}^{\mathbf{b}}$ & $\mathbf{S F T}^{\mathbf{c}}$ & $\mathbf{C T E}_{\mathbf{c}}{ }^{\mathbf{d}}$ & $\begin{array}{c}\mathbf{1} / \mathbf{R}^{\mathbf{e}} \\
{\left[\mathbf{m m}^{-1}\right]}\end{array}$ & $\begin{array}{c}\boldsymbol{\sigma}_{\mathbf{t h}^{\mathbf{f}}} \\
{[\mathbf{M P a}]}\end{array}$ \\
\hline Neat & 3241 & 0.018 & 125 & 87 & 0.0169 & 16.4 \\
\hline $5 \%$ PEI8 & 2796 & 0.016 & 119 & 83 & 0.0146 & 12.5 \\
\hline $10 \%$ PEI8 & 2626 & 0.015 & 113 & 85 & 0.0137 & 11.2 \\
\hline $20 \%$ PEI8 & 2203 & 0.012 & 104 & 92 & 0.0129 & 9.1 \\
\hline $5 \%$ PEI250 & 2687 & 0.015 & 109 & 93 & 0.0145 & 12.1 \\
\hline $10 \%$ PEI250 & 2505 & 0.014 & 105 & 95 & 0.0139 & 10.9 \\
\hline $20 \%$ PEI250 & 1782 & 0.010 & 96 & 102 & 0.0123 & 7.4 \\
\hline
\end{tabular}

${ }^{a}$ Elastic modulus determined by DMTA.

${ }^{\mathrm{b}}$ Ratio of coating and substrate module $\alpha=E_{\mathrm{c}} / E_{\mathrm{s}}$.

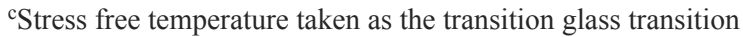
temperature determined by TMA.

${ }^{\mathrm{d}}$ Thermal expansion coefficient in the glassy state determined by TMA.

${ }^{e}$ Curvature determined using Equation (7).

${ }^{\mathrm{f}}$ Thermal stress determined using Equation (8).

increases slightly. Although this increase tends to increase the stresses, the lower $E_{\mathrm{c}}$ and $S F T$ values of PEI250 formulations compensate this effect leading to significant reduction of thermal stress. This reduction is higher for PEI250 formulations than for PEI8 formulations and the highest reduction of $\sigma_{\text {th }}$ is achieved by adding a $20 \%$ of PEI 250 . These results agree, again, with the higher flexibility and lower crosslinking density induced by the presence of PEI250 and its possible participation in the curing process.

\subsection{Mechanical characterization and morphology}

The toughness behaviour of all cured formulations was investigated by impact test and the morphology was analyzed by SEM on the impacted fracture. Figure 9 shows that both PEI250 and PEI8 produce a significant increase in the impact strength of the cured materials, proportional to the amount of modifier used. This increase is more than $100 \%$ with respect to the neat formulation, for thermosets containing a $20 \%$ of both modifiers. This result is consistent with a phase-separated morphology, where soft particles of modifier adhered to the epoxy/ anhydride matrix absorb energy during impact test, although the DMA and DSC results showing a decrease in the $T_{\mathrm{g}}$ of the cured material suggest also some enhancement in the matrix shear yielding. The degree of interfacial adhesion between the soft phase and the matrix is critical in toughening. Effective toughening is believed to occur with an intermedi-

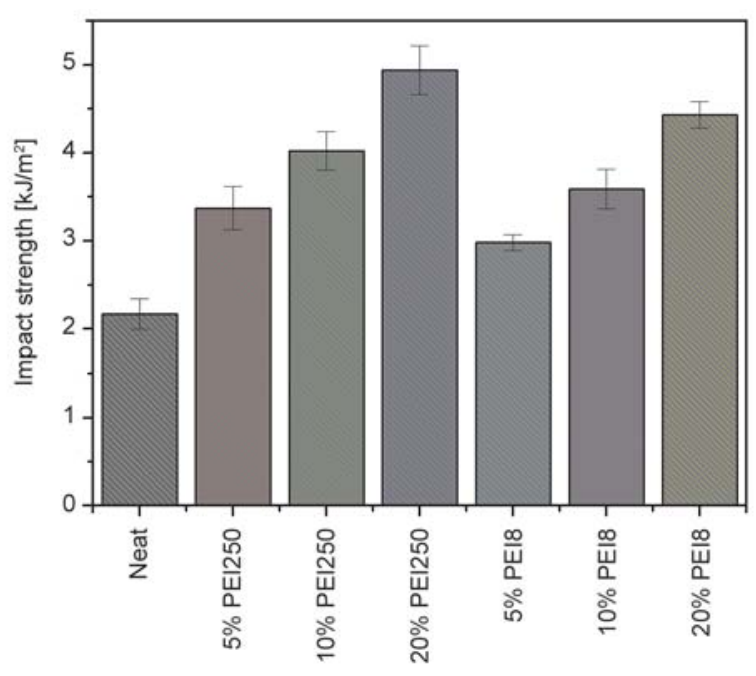

Figure 9. Impact strength for neat DGEBA/anhydride and thermosets with PEI250 and PEI8

ate interfacial bonding, since an excessive adhesion can deteriorate the interfacial adhesion between the toughener phase and the matrix [36]. In previous works we observed that polymeric modifiers with excessive physical-chemical compatibility with the matrix led to their covalent incorporation into the network structure, preventing phase separation and producing very little toughness enhancement, whereas polymers that phase-separate during curing but with certain physical-chemical compatibility with the matrix led to the highest increase in impact strength [14]. Although it is not possible to know the amount of amine groups that react during curing, it is reasonable assuming the formation of some covalent bonds between the remaining amine groups at the core of the star polymer and the epoxy groups. Although the addition of both stars increases toughness characteristics the improvement achieved with PEI250 is higher. The amount of covalent bonds formed between matrix and modifier, the higher flexibility of PEI250 and the resulting polymer matrix and the lower thermal stress in PEI250 formulations can justify the differences observed between PEI250 and PEI8 thermosets.

Figure 10 shows some SEM micrographs of the fractured surfaces of materials after impact tests. In previous works it was observed that the fracture of the neat DGEBA/anhydride formulation is relatively smooth and glassy and does not show any significant morphological features, due to the formation of a homogeneous material $[20,37]$. On the contrary, materials containing PEI8 and PEI250 (Figure 7) show a characteristic morphology completely differ- 

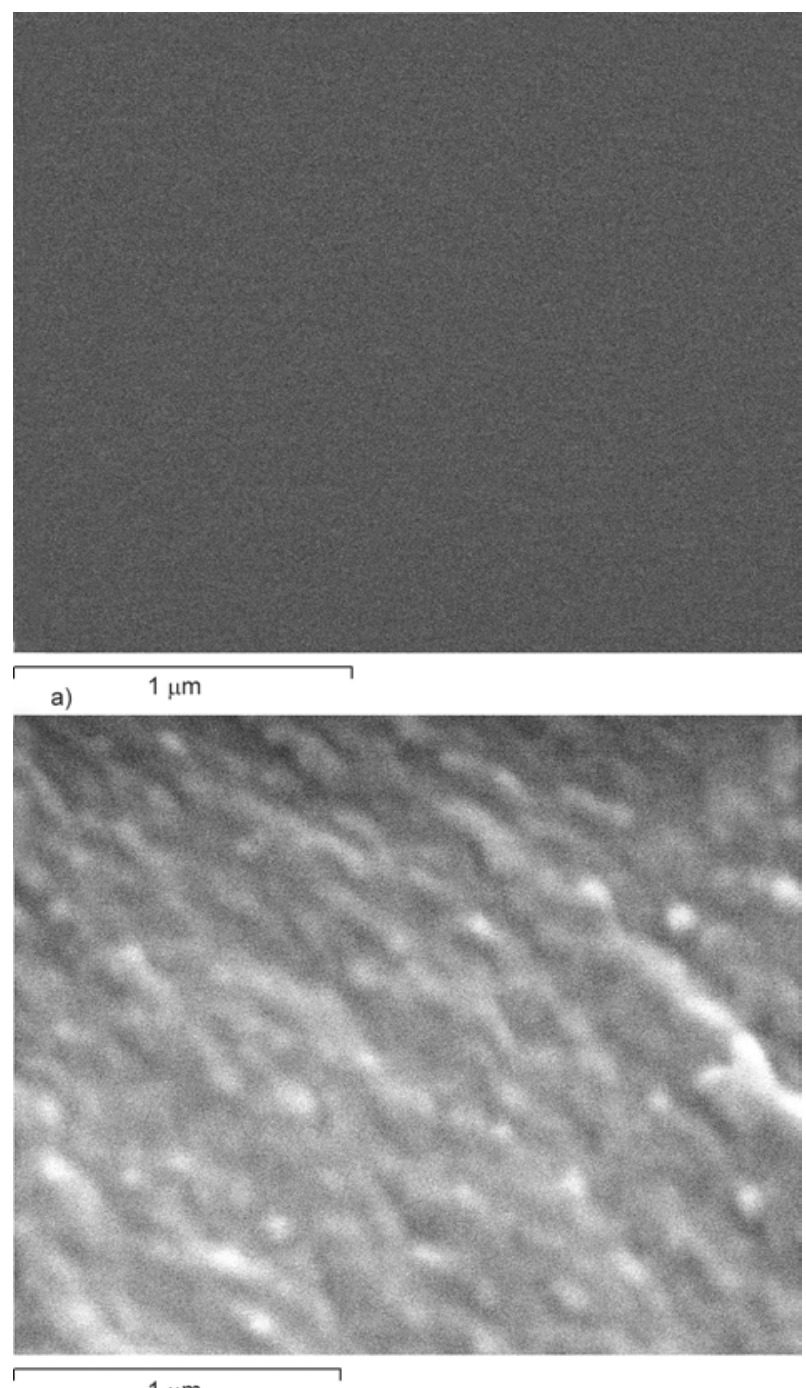

b)

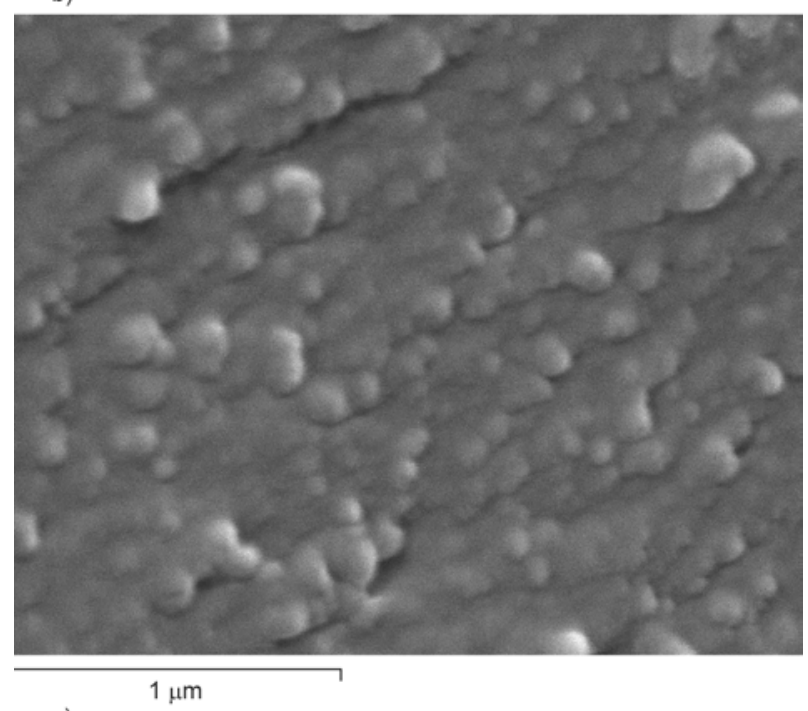

c)

Figure 10. SEM micrographs at 50000 magnifications of the fractured surfaces of the materials obtained from a) neat, b) 10\% PEI8 and c) 10\% PEI250 formulations ent from that of the neat formulation. PEI8 micrographs present nanograined morphology with nanosized grains. This nanopatterned organization can be attributed to the presence of amino groups, which can react during curing with epoxides changing the morphology in the surrounding of the star polymer. In a previous study [20] on the modification of DGEBA/anhydride thermosets with star polymers we could observe that the presence of reactive groups in the star led to homogeneous materials, whereas the blocking of these reactive groups produced nanograined morphology. In the present case, PEI8 has a high content of blocked groups and a low content of amine reactive groups, leading to the nanostructure observed by SEM inspection. PEI250 thermosets show a phase-separated morphology with nanosized $(75$ to $150 \mathrm{~nm}$ ) fine particles well adhered to the epoxy/anhydride matrix. It can be hypothesized that these particles are formed by PEI250 surrounded by epoxy/anhydride matrix covalently bonded to PEI250 but some aggregation of star polymers cannot be excluded. The differences between two morphologies can be attributed to the different molecular weight of the star polymer and to the amount of amine groups of star polymer that reacts during curing. Although both morphologies lead to significant toughness enhancement in the materials, phase-separated morphology produces a slightly higher improvement than nanograined morphology.

\section{Conclusions}

The curing of epoxy/anhydride systems in the presence of PEI8 and PEI250 and tertiary amines mainly proceeds by anionic alternating copolymerization catalyzed by tertiary amines, although the uncatalyzed epoxy-anhydride polycondensation and the epoxy-amine reaction can take place to some extent.

The addition of star polymers with poly(ethyleneimine) cores and blocked poly( $\varepsilon$-caprolactone) arms to epoxy/anhydride formulations allows to obtain thermosets with significant improved toughness and low thermal stress generation during cooling, with only a slight reduction on glass transition temperature and crosslinking density.

The flexibility and molecular weight of the star modifiers used, as well as the amount of amino reactive groups in the modifier affect the morphology of the 
resulting thermosets but only slightly their thermomechanical properties and curing process. The use of high molecular weight modifier with blocked terminal groups leads to phase-separated morphologies with nano-sized fine particles well adhered to the epoxy/anhydride matrix by the presence of unreacted amine groups.

\section{Acknowledgements}

The authors would like to thank MICINN (Ministerio de Ciencia e Innovación) and FEDER (Fondo Europeo de Desarrollo Regional) (MAT2014-53706-C03-01 and MAT2014-53706-C03-02) and to the Comissionat per a Universitats i Recerca del DIUE de la Generalitat de Catalunya (2014-SGR-67).

\section{References}

[1] May C. A.: Introduction to epoxy resins. in 'Epoxy resins. Chemistry and technology' (ed.: May C. A.) Marcel Dekker, New York, 1-8 (1988).

[2] Bauer R. S.: Epoxy resin chemistry I. American Chemical Society, Washington (1979).

[3] Pascault J. P., Williams R. J. J.: Epoxy polymers: New materials and innovations. Wiley- $\mathrm{VCH}$, Weinheim (2010).

[4] Lange J., Toll S., Månson J-A. E.: Residual stress buildup in thermoset films cured above their ultimate glass transition temperature. Polymer, 36, 3135-3141 (1995). DOI: 10.1016/0032-3861(95)97876-H

[5] Thomas R., Durix S., Sinturel C., Omonov T., Goossens S., Groeninckx G., Moldenaers P., Thomas S.: Cure kinetics, morphology and miscibility of modified DGEBA-based epoxy resin - Effects of a liquid rubber inclusion. Polymer, 48, 1695-1710 (2007).

DOI: $10.1016 /$ j.polymer.2007.01.018

[6] Mijovic J., Shen M., Sy J. W., Mondragon I.: Dynamics and morphology in nanostructured thermoset network/block copolymer blends during network formation. Macromolecules, 33, 5235-5244 (2000).

DOI: $10.1021 / \mathrm{ma} 991894 \mathrm{e}$

[7] Choi J., Yee A. F., Laine R. M.: Toughening of cubic silsesquioxane epoxy nanocomposites using coreshell rubber particles: A three-component hybrid system. Macromolecules, 37, 3267-3276 (2004).

DOI: $10.1021 / \mathrm{ma} 0303723$

[8] Mezzenga R., Boogh L., Månson J-A. E.: A review of dendritic hyperbranched polymer as modifiers in epoxy composites. Composites Science and Technology, 61, 787-795 (2001).

DOI: 10.1016/S0266-3538(01)00022-7

[9] Morell M., Ramis X., Ferrando F., Serra A.: Effect of polymer topology on the curing process and mechanical characteristics of epoxy thermosets modified with linear or multiarm star poly( $\varepsilon$-caprolactone). Polymer, 52, 4694-4702 (2011).

DOI: $10.1016 /$ j.polymer.2011.07.040
[10] Ratna D., Varley R., Simon G. P.: Toughening of trifunctional epoxy using an epoxy-functionalized hyperbranched polymer. Journal of Applied Polymer Science, 89, 2339-2345 (2003).

DOI: 10.1002 app.12059

[11] Flores M., Fernández-Francos X., Ferrando F., Ramis X., Serra A.: Efficient impact resistance improvement of epoxy/anhydride thermosets by adding hyperbranched polyesters partially modified with undecenoyl chains. Polymer, 53, 5232-5241 (2012). DOI: $10.1016 /$ j.polymer.2012.09.031

[12] Lagunas C., Fernández-Francos X., Ferrando F., Flores M., Serra A., Morancho J. M., Salla J. M., Ramis X.: New epoxy thermosets modified with amphiphilic multiarm star polymers as toughness enhancer. Reactive and Functional Polymers, 83, 132-143 (2014). DOI: 10.1016/j.reactfunctpolym.2014.07.022

[13] Tomuta A., Ramis X., de la Flor S., Serra A.: Influence of end groups in hyperbranched polyesters used as modifiers in the characteristics of epoxy thermosets cured by adipic dihydrazide. Express Polymer Letters, 7, 595-606 (2013).

DOI: 10.3144/expresspolymlett.2013.57

[14] Luo L., Meng Y., Qui Y., Li X.: An epoxy-ended hyperbranched polymer as a new modifier for toughening and reinforcing in epoxy resin. Journal of Applied Polymer Science, 130, 1064-1073 (2013).

DOI: 10.1002/app.39257

[15] Zhang D., Chen Y., Jia D.: Toughness and reinforcement of diglycidyl ether of bisphenol-A by hyperbranched poly(trimellitic anhydride-butanediol glycol) ester epoxy resin. Polymer Composites, 30, 918-925 (2009).

DOI: $10.1002 / p c .20633$

[16] Liu T., Nie Y., Chen R., Zhang L., Meng Y., Li X.: Hyperbranched polyether as an all-purpose epoxy modifier: Controlled synthesis and toughening mechanisms. Journal of Materials Chemistry A, 3, 1188-1198 (2015). DOI: $10.1039 / \mathrm{c} 4$ ta04841e

[17] Acebo C., Fernández-Francos X., Ferrando F., Serra A., Salla J. M., Ramis X.: Multiarm star with poly(ethyleneimine) core and poly( $\varepsilon$-caprolactone) arms as modifiers of diglycidylether of bisphenol A thermosets cured by 1-methylimidazole. Reactive and Functional Polymers, 73, 431-441 (2012).

DOI: $10.1016 /$ j.reactfunctpolym.2012.11.007

[18] Acebo C., Fernández-Francos X., Ferrando F., Serra A., Ramis X.: New epoxy thermosets modified with multiarm star poly(lactide) with poly(ethyleneimine) as core of different molecular weight. European Polymer Journal, 49, 2316-2326 (2013).

DOI: $10.1016 /$ j.eurpolymj.2013.05.015

[19] Morell M., Erber M., Ramis X., Ferrando F., Voit B., Serra A.: New epoxy thermosets modified with hyperbranched poly(ester-amide) of different molecular weight. European Polymer Journal, 46, 1498-1509 (2010).

DOI: $\underline{10.1016 / j . e u r p o l y m j .2010 .04 .015}$ 
[20] Acebo C., Picardi A., Fernández-Francos X., de la Flor S., Ramis X., Serra A.: Effect of hydroxyl ended and end-capped multiarm star polymers on the curing process and mechanical characteristics of epoxy/anhydride thermosets. Progress in Organic Coatings, 77, 1288-1298 (2014).

DOI: 10.1016/j.porgcoat.2014.04.014

[21] González S., Fernández-Francos X., Salla J. M., Serra A., Mantecón A., Ramis X.: New thermosets obtained by cationic copolymerization of DGEBA with $\gamma$-caprolactone with improvement in the shrinkage. II. Timetemperature-transformation (TTT) cure diagram. Journal of Applied Polymer Science, 104, 3406-3416 (2007).

DOI: $10.1002 / a p p .26021$

[22] Flores M., Fernández-Francos X., Ramis X., Serra A.: Novel epoxy-anhydride thermosets modified with a hyperbranched polyester as toughness enhancer. I. Kinetics study. Thermochimica Acta, 544, 17-26 (2012). DOI: $10.1016 /$ j.tca.2012.06.008

[23] Benabdi M., Roche A. A.: Mechanical properties of thin and thick coatings applied to various substrates. Part I. An elastic analysis of residual stresses within coating materials. Journal of Adhesion Science and Technology, 11, 281-299 (1997).

DOI: $10.1163 / 156856197 X 00363$

[24] Fernández-Francos X., Rybak A., Sekula R., Ramis X., Serra A.: Modification of epoxy-anhydride thermosets using a hyperbranched poly(ester-amide): I. Kinetic study. Polymer International, 61, 1710-1725 (2012). DOI: 10.1002/pi.4259

[25] Santiago D., Fernández-Francos X., Ramis X., Salla J. M., Sangermano M.: Comparative curing kinetics and thermal-mechanical properties of DGEBA thermosets cured with a hyperbranched poly(ethyleneimine) and an aliphatic triamine. Thermochimica Acta, 526, 9-21 (2011).

DOI: $10.1016 /$ j.tca.2011.08.016

[26] Fernández-Francos X., Santiago D., Ferrando F., Ramis X., Salla J. M., Serra A., Sangermano M.: Network Structure and thermomechanical properties of hybrid DGEBA Networks cured with 1-methylimidazole and hyperbranched poly(ethyleneimine)s. Journal of Polymer Science Part B: Polymer Physics, 50, 1489-1503 (2012).

DOI: $10.1002 /$ polb.23145

[27] Mauri A. N., Riccardi C. C.: The effect of epoxy excess on the kinetics of an epoxy-anhydride system. Journal of Applied Polymer Science, 85, 2342-2349 (2002). DOI: 10.1002/app.10867
[28] Rocks J., Rintoul L., Vohwinkel F., George G.: The kinetics and mechanism of cure of an amino-glycidyl epoxy resin by a co-anhydride as studied by FT-Raman spectroscopy. Polymer 45, 6799-6811 (2004). DOI: $10.1016 /$ j.polymer.2004.07.066

[29] Leonard J.: Heats and entropies of polymerization, ceiling temperatures, equilibrium monomer concentrations, and polymerizatbility of heterocyclic compounds. in 'Polymer handbook' (eds.: Brandrup J., Immermut E. H., Grulke E. A.) Wiley-Intersecience, New York, Vol 1, II/363-II/407 (1999).

[30] Dušek K., Luňák S., Matějka L.: Gelation in the curing of epoxy resins with anhydrides. Polymer Bulletin 7, 144-152 (1982).

DOI: $10.1007 / \mathrm{BF} 00265465$

[31] Mauri A. N., Galego N., Riccardi C. C., Williams R. J. J.: Kinetic model for gelation in the diepoxide-cyclic anhydride copolymerization initiated by tertiary amines. Macromolecules, 30, 1616-1620 (1997).

DOI: $10.1021 / \mathrm{ma9614048}$

[32] Fernandez-Francos X., Ramis X., Serra A.: From curing kinetics to network structure: A novel approach to the modeling of the network buildup of epoxy-anhydride thermosets. Journal of Polymer Science Part A: Polymer Chemistry, 52, 61-75 (2014).

DOI: $10.1002 /$ pola.26972

[33] Liu T., Nie Y., Zhang L., Chen R., Meng Y., Li X.: Dependence of epoxy toughness on the backbone structure of hyperbranched polyether modifiers. RCS Advances, 5, 3408-3416 (2015).

DOI: $10.1039 / \mathrm{c} 4 \mathrm{ra10974k}$

[34] Miao X., Meng Y., Li X.: A novel all-purpose epoxyterminated hyperbranched polyether sulphone toughener for an epoxy/amine system. Polymer, 60, 88-95 (2015).

DOI: $10.1016 /$ j.polymer.2015.01.034

[35] Pascault J. P., Sautereau H., Verdu J., Williams R. J. J.: Thermosetting polymers. Marcel Dekker, New York (2002).

[36] Sue H-J., Garcia-Meitin E. I., Pickelman D. M.: Fracture behavior of rubber-modified high performance epoxies. in 'Polymer toughening' (ed.: Arends C. B.) Marcel Dekker, New York, 131-174 (1996).

[37] Tomuta A., Fernández-Francos X., Ferrando F., Serra A., Ramis X.: New epoxy-anhydride thermosets modified with multiarm stars with hyperbranched polyester cores and poly( $€$-caprolactone) arms. Polymer-Plastics Technology and Engineering, 53, 645-654 (2014). DOI: $10.1080 / 03602559.2013 .869599$ 